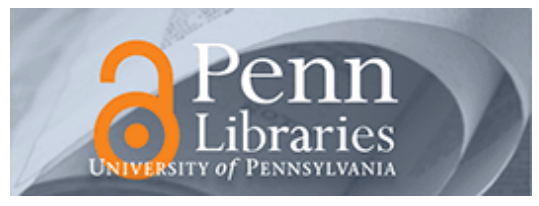

University of Pennsylvania

ScholarlyCommons

Finance Papers

Wharton Faculty Research

2017

\title{
Online and Offline Information for Omnichannel Retailing
}

Fei Gao

Xuanming Su

University of Pennsylvania

Follow this and additional works at: https://repository.upenn.edu/fnce_papers

Part of the Finance and Financial Management Commons

\section{Recommended Citation}

Gao, F., \& Su, X. (2017). Online and Offline Information for Omnichannel Retailing. Manufacturing \& Service Operations Management, 19 (1), 84-98. http://dx.doi.org/10.1287/msom.2016.0593

This paper is posted at ScholarlyCommons. https://repository.upenn.edu/fnce_papers/132

For more information, please contact repository@pobox.upenn.edu. 


\title{
Online and Offline Information for Omnichannel Retailing
}

\begin{abstract}
This paper studies how retailers can effectively deliver online and offline information to omnichannel consumers who strategically choose whether to gather information online or offline and whether to buy products online or offline. Information resolves two types of uncertainty: product value uncertainty (i.e., consumers realize valuations when they inspect the product in store, but may end up returning the product when they purchase online) and availability uncertainty (i.e., store visits are futile when consumers encounter stockouts). We consider three information mechanisms: physical showrooms allow consumers to learn valuations anytime they visit the store, even during stockouts; virtual showrooms give consumers online access to an imperfect signal of their valuations; availability information provides real-time information about whether the store has a product in stock. Our main results follow. First, physical showrooms may prompt retailers to reduce store inventory, which increases availability risk and discourages store patronage. Second, virtual showrooms may increase online returns and hurt profits, if they induce excessive customer migration from store to online channels. Third, availability information may be redundant when availability risk is low and may render physical showrooms ineffective when implemented jointly. Finally, when customers are homogeneous, these mechanisms may not exhibit significant complementarities and the optimal information structure may involve choosing only one of the three.
\end{abstract}

\section{Keywords}

retail operations, strategic consumer behavior, inventory availability, product value uncertainty, omnichannel

Disciplines

Business | Finance and Financial Management 


\title{
Online and Offline Information for Omnichannel Retailing
}

\author{
Fei Gao
}

The Wharton School, University of Pennsylvania, Philadelphia, PA, 19104

feigao@wharton.upenn.edu

Xuanming $\mathrm{Su}$

The Wharton School, University of Pennsylvania, Philadelphia, PA, 19104

xuanming@wharton.upenn.edu

\begin{abstract}
This paper studies how retailers can effectively deliver online and offline information to omnichannel consumers who strategically choose whether to gather information online/offline and whether to buy products online/offline. Information resolves two types of uncertainty: product value uncertainty (i.e., consumers realize valuations when they inspect the product in store, but may end up returning the product when they purchase online) and availability uncertainty (i.e., store visits are futile when consumers encounter stockouts). We consider three information mechanisms: physical showrooms allow consumers to learn valuations anytime they visit the store, even during stockouts; virtual showrooms give consumers online access to an imperfect signal of their valuations; availability information provides real-time information about whether the store is in stock. Our main results follow. First, physical showrooms may prompt retailers to reduce store inventory, which increases availability risk and discourages store patronage. Second, virtual showrooms may increase online returns and hurt profits, if they induce excessive customer migration from store to online channels. Third, availability information may be redundant when availability risk is low, and may render physical showrooms ineffective when implemented jointly. Finally, when customers are homogeneous, these mechanisms may not exhibit significant complementarities and the optimal information structure may involve choosing only one of the three.
\end{abstract}

Keywords: retail operations; strategic consumer behavior; inventory availability; product value uncertainty; omnichannel 


\section{Introduction}

In the present world of constant connectivity, the consumer's journey from product discovery to eventual purchase often involves multiple shopping channels (UPS, 2014). It is not uncommon for shoppers to browse products in stores and then place an order online, or to extensively research products online before completing the purchase in a physical store (Brynjolfsson et al., 2013). Consumers are becoming sophisticated enough to optimize their shopping experience by exhaustively considering all possible alternatives across all possible channels. As a result, retailers face immense pressure to integrate the best of both digital and physical worlds at each step of the customer experience (Rigby, 2011). This is the spirit of omnichannel retailing, which is fast becoming the norm in the industry (Forrester, 2014). One of the greatest challenges in the omnichannel environment is to effectively deliver information (Bell et al., 2014). As consumers actively seek information about product value and inventory availability, retailers can influence shopping paths by managing the sources of information. In this paper, our goal is to understand how information influences omnichannel consumer behavior and retailer performance.

Displaying products in a showroom is one of the most common ways for retailers to convey product information to consumers. Typically, consumers can inspect the line of products on display whenever they come to the store. Although most commonly implemented in stores of home furniture and consumer electronics, the idea of showrooms has also been recently adopted by fashion e-tailers such as Bonobos and Warby Parker (New York Times, 2014; Wall Street Journal, 2014). These companies have set up pure showrooms with products purely for display purposes: customers finding something they like in the showrooms can make a purchase by placing an order on the corresponding website. Although pure showrooms may carry a small amount of inventory, their primary function is information rather than fulfillment; Bell et al. (2015) demonstrate that the former can help generate profits by reducing online returns. In this sense, setting up showrooms can be a useful strategy for omnichannel retailers.

In recent years, showrooms have moved from physical into digital domains. With the development of virtual reality technology, online shoppers can now try on different products as if they were in the store (Financial Times, 2011). For example, on the website of BonLook, an eyewear retailer, consumers can upload their own photos to see how different frames will look on their digital faces. Similarly, on the website of UK luxury shirt brand Thomas Pink, consumers can check the fit of a 
shirt through a digital avatar. Many advanced technologies are now available from an increasing variety of providers. For example, Metail provides visualization technology that creates 3D models of shoppers based on a few customized measurements, while Shoefitr uses 3D scanning technology to measure the insides of shoes with accuracy up to a quarter of a millimeter (CNET, 2010). With these advances, virtual showrooms are no longer a figment of imagination as shoppers can now experience products first-hand anywhere and anytime. As online channels face more pressure from product returns, which are estimated to account for a third of all Internet sales (Wall Street Journal, 2013b), virtual showrooms will likely become a potential remedy (Bell et al., 2014; CNBC, 2015).

While product uncertainty may discourage purchase, availability uncertainty may discourage patronage. Recognizing this customer concern, many retailers have started to provide real-time store availability information online. Shoppers can simply enter a zip code to check the current status of nearby stores (e.g., whether or not a product is in stock, or how much inventory is available). In fact, many retailers go a step further, allowing customers to complete the transaction online and pick up their order in the store shortly after; recent studies of this buy-online-pickup-instore option (Gallino and Moreno, 2014, Gao and Su, 2016) highlight the importance of availability information. Simply put, some customers will shop in a store only if they know that a product is in stock.

In this paper, we study the following three types of information mechanisms. Physical showrooms allow consumers to inspect products in the store even when it is out of stock; this may involve setting aside units as permanent display models. Virtual showrooms, by mimicking physical presence, enable online shoppers to evaluate products without coming to the store; product value uncertainty is reduced but still present because technology is never perfect. Availability information allows customers who have not visited the store to learn whether it is in or out of stock, so that they may choose a different shopping path in each case. What is the impact of each of these three mechanisms? Which combination should a retailer implement? These are the research questions that we study in this paper.

To address these questions, we develop a stylized model that captures essential elements of omni-channel retail environments. There is a retailer who operates online and store channels. Consumers strategically make channel choices to maximize individual utility. An important feature of our model is that consumers face product value uncertainty. Consumers who visit the store can 
inspect the product (if it is in stock) to fully learn their valuation before deciding whether to purchase; however, consumers who purchase online may later realize that they do not like the product and end up returning it. Demand is random. In the store channel, the retailer chooses a stocking quantity before demand is realized and may end up with leftovers or stockouts; however, in the online channel, the retailer obtains supply after demand is realized and is hence able to satisfy all orders. In our analysis, we first study each information mechanism (i.e., physical showrooms, virtual showrooms, or availability information), and then we examine potential interaction effects among them to determine the optimal information structure.

We summarize our main findings below.

First, physical showrooms attract customers to the store because they help customers resolve product value uncertainty regardless of whether the product is in or out of stock. In particular, during stockouts, shoppers who learn from the showroom display that they do not like the product can avoid making an unnecessary purchase online. In this way, physical showrooms help to reduce returns from customers who encounter a stockout in store, substitute online, and then return the product (which may lead to a net loss). Although physical showrooms reduce the cost of stockouts, they create a temptation for retailers to lower store inventory levels, and customers who are sensitive to availability risk may prefer to buy online instead. This leads to more returns and lower profit. Our results thus caution that physical showrooms are not always profitable, and retailers should make the best effort to maintain satisfactory inventory service levels in stores equipped with showrooms.

Second, virtual showrooms reduce product value uncertainty online, by screening out consumers who do not like the product before any purchase takes place. Understandably, returns go down and profits go up. However, our results raise another red flag. Sometimes, virtual showrooms make online shopping so attractive that customers who were originally shopping in store choose to migrate online. When there is significant customer migration online, total returns may go up (even as return rates go down) simply because many more customers are buying online before product value is completely ascertained (recall that virtual showrooms reduce but do not completely eliminate product value uncertainty). Therefore, our results suggest that virtual showrooms are profitable as long as they do not induce too much customer migration to the online channel.

Third, availability information eliminates availability risk and thus attracts customers to the store. Although availability information may sometimes be redundant (e.g., when consumers are 
already willing to visit the store even without availability information), it does not hurt profits when implemented on its own. However, when implemented together with showrooms, it may hamper their effectiveness. For example, suppose a retailer with physical showrooms now offers availability information as well. Then, when the store is in stock, customers may show up and be able to learn their valuation from the physical showroom; however, once customers realize that the store is out of stock, they may not show up. In this sense, providing availability information makes physical showrooms less useful.

Finally, the information mechanisms studied above do not exhibit significant complementarities because there are potential overlaps in how they impact consumer behavior. Specifically, physical showrooms and availability information both attract customers to the store, and both physical and virtual showrooms mitigate product value uncertainty. Given these overlaps, the optimal information structure often involves choosing one of the three mechanisms. For products that are traditionally afflicted with high online return rates, retailers should establish physical showrooms; however, for products with relatively more manageable online return rates, retailers should consider implementing virtual showrooms, and possibly also provide availability information to maintain the attractiveness of the store channel.

\section{Literature Review}

This paper studies the management of online and offline channels. The traditional literature on channel management focuses on the situation where different channels are operated by different companies, e.g., Chiang et al. (2003), Cattani et al. (2006), Chen et al. (2008), and Netessine and Rudi (2006). In contrast to this stream of work, our paper focuses on an omnichannel environment, where a retailer operates both online and offline channels in an integrated way (Bell et al., 2014. Brynjolfsson et al., 2013, Rigby, 2011). In this environment, most operations management papers focus on new omnichannel fulfillment methods. For example, Gallino and Moreno (2014) empirically test the impact of buy-online-and-pickup-in-store (BOPS) on a retailer's sales in both online and offline channels, while Gao and $\mathrm{Su}(2016)$ study the implementation of BOPS and its implications on channel coordination from a theoretical perspective. Gallino et al. (2014) investigate another widely-used omnichannel fulfillment option, i.e., ship-to-store, and empirically demonstrate that within a group of SKUs, the share of sales of bottom-selling items increases. In contrast to 
these papers, we focus how to effectively provide information to consumers in the omnichannel environment. A closely related paper is Bell et al. (2015), which studies the impact of physical showrooms on consumers' channel choice. They find that with the introduction of physical showrooms, customers with a greater need for product information self-select into the physical channel, leading to reduced online returns and increased overall demand. In this paper, we study physical showrooms, as well as virtual showrooms and availability information.

There is a large literature devoted to the question of how a firm can induce purchases from consumers facing product value uncertainty. The most widely studied mechanism is product returns. Che (1996) and Davis et al. (1995) consider the case where a seller offers full refunds (or money-back guarantees). Davis et al. (1998) focus on the consumer hassle costs during the return process, and Moorthy and Srinivasan (1995) show that full refunds can signal product quality. More recent papers study partial refund policies in conjunction with supply chain contracts $(\mathrm{Su}$, 2009), overbooking (Gallego and Sahin, 2010), demand cannibalization (Akçay et al., 2013), and strategic waiting for discounts (Altug and Aydinliyim, 2015); another paper by Hsiao and Chen (2012) finds that sellers of low-quality products may have to offer a refund that exceeds the selling price. The papers above study how returns/refunds can be used to limit the downside of a bad purchase, but in this paper, one of our goals is to reduce the incidence of bad purchases in the first place. To this end, our physical and virtual showrooms directly reduce product value uncertainty by allowing consumers to experience products prior to purchase. Ultimately, showrooms and returns policies complement each other because they serve different functions: while returns policies provide insurance against consumer loss, showrooms provide product value information.

There is a stream of literature on using product availability as a strategic lever to attract demand. Being averse to stockouts, consumers may be reluctant to incur the hassle of going to a store. This practical issue has motivated much work in operations management. Following the classic paper by Dana and Petruzzi (2001), which extends the newsvendor model by endogenizing demand as a function of both price and inventory level, many papers have looked at different strategies to influence consumers' shopping decisions. Su and Zhang (2009) show that it is always beneficial to the retailer if he can credibly make an ex ante quantity commitment. Yin et al. (2009) investigate the impact of two different display formats, i.e., display-all versus display-one. Allon and Bassamboo (2011) study a situation where a retailer could share unverifiable and nonbinding (i.e., cheap talk) inventory information with consumers. Alexandrov and Lariviere $(2012)$ examine 
the role of reservations in the context of revenue management. Cachon and Feldman (2015) study dynamic pricing and find that frequent discounts can attract customers to the store. In contrast to the previous studies, in this paper, we consider a different mechanism where a retailer shares real-time store availability information that reflects the current inventory level available to each individual customer.

This paper also adds to the growing literature on strategic customer behavior in retail management. This literature mostly focuses on dynamic pricing strategies when consumers strategically wait for potential price discounts in the future ( $\mathrm{Su}, 2007$, Aviv and Pazgal, 2008); more recent work has incorporated competition (Levin et al., 2009), binding reservations Osadchiy and Vulcano (2010), opaque selling (Jerath et al., 2010), demand learning (Mersereau and Zhang, 2012), social learning (Papanastasiou and Savva, 2014), and cyclic pricing (Besbes and Lobel, 2015). Another stream of literature focuses on the impact of different operational strategies when consumers strategically wait for discounts: e.g., capacity rationing (Liu and van Ryzin, 2008), supply chain contracting (Su and Zhang, 2008), quick response (Cachon and Swinney, 2009, Swinney, 2011), and product launches (Liang et al., 2014; Lobel et al., 2014). Our paper provides a different angle to this stream of work. Instead of considering the situation where consumers decide when to make a purchase, we focus on a business environment where consumers strategically decide where to buy a product.

\section{Base Model}

There is a retailer who sells a product through two channels, store and online, at price $p$. In the store channel, the retailer faces a newsvendor problem: there is a single inventory decision $q$ to be made before random demand is realized, so there may eventually be unmet demand or leftovers in the store. The unit cost of inventory is $c$, which includes the production/procurement cost and other store-related costs, e.g., the transportation cost of shipping the product to store and the inventory holding cost in store. Leftover units have no value. The online channel is modeled exogenously: for each unit sold online, the retailer obtains a net profit margin $w$ if it is not returned, and incurs a net loss $r$ otherwise.

The market demand $D$ is random and follows distribution $F$. A fraction of $\theta \in(0,1)$ of the population has positive value $v$ for the product, and a fraction $1-\theta$ has zero value. We 
refer to the former as "high types," the latter as "low types," and the parameter $\theta$ as the "hightype probability." Customers are homogeneous ex ante: they don't know their valuation (or type) beforehand, but $\theta$ and $v$ are common knowledge. Customers may learn their valuations before purchase only if they examine the product in store; otherwise, customers learn valuations after purchase. In particular, online purchases may be returned, as described below.

Each consumer makes a choice between shopping online directly or going to the store. If she chooses to buy online directly, she incurs hassle cost $h_{o}$ (e.g., paying shipping fees or waiting for the product to arrive), and realizes her valuation only after receiving the product. If she likes the product (i.e., she is high type), then she keeps it and receives payoff $v-p-h_{o}$; if she dislikes the product (i.e., she is low type), then she returns it. Returns are costly to both the retailer and the consumers: each returned unit generates net loss $r>0$ to the retailer and an additional hassle cost $h_{r}>0$ to the consumer. We assume that low type consumers prefer returning the product to keeping it, i.e., $h_{r}<p$. Therefore, the consumer's expected payoff from buying online directly is given by

$$
u_{o}=\theta\left(v-p-h_{o}\right)-(1-\theta)\left(h_{o}+h_{r}\right)
$$

On the other hand, if the consumer chooses to go to the store, she has to first incur hassle $\operatorname{cost} h_{s}$ (e.g., traveling to the store or searching for the product in aisles). We stress that the store hassle cost $h_{s}$ is incurred before customers find and purchase the product in the store, whereas the online hassle cost $h_{o}$ above is incurred after customers make the purchase online. Once she is in the store, the customer may encounter two possible outcomes: (1) If the store is in stock, then she can evaluate the product on the spot: a high type makes a purchase and receives payoff $v-p$, while a low type leaves without any purchase and receives payoff 0. (2) If the store is out of stock, she cannot resolve her value uncertainty in store, but she can buy the product online and receive an expected payoff $u_{o}$ instead. Let $\xi$ denote the probability that the store is in stock, and let $\hat{\xi}$ denote consumers' beliefs about this probability; throughout this paper, we use the hat notation ^ to denote beliefs. We assume that customers arrive sequentially to the market, all customer permutations are equally likely, and customers do not know their order of arrival. As a result, everyone has the same belief $\hat{\xi}$. Then, given belief $\hat{\xi}$, each consumer's payoff from visiting the store can be expressed as follows:

$$
u_{s}(\hat{\xi})=-h_{s}+\hat{\xi} \theta(v-p)+(1-\hat{\xi}) u_{o}
$$


Consumers compare the expected utility from each channel and chooses accordingly. In the spirit of omnichannel choice, i.e., consumers are willing to consider both channels, we assume $v$ is large enough so that $u_{s}(1) \geq 0$ and $u_{o} \geq 0$.

Next, we consider the retailer's decision problem. First, the retailer anticipates that a fraction $\hat{\phi} \in[0,1]$ of customers will visit the store. Then, if total demand is $D$, the retailer expects that the number of customers coming to the store will be $\hat{\phi} D$; also, since only high-type customers will eventually make a purchase in the store, given the store inventory level $q$, the retailer expects that the number of store customers who find that the store is in stock is $D_{i n}(q)=\min \left(\hat{\phi} D, \frac{q}{\theta}\right)$, and the remaining $D_{\text {out }}(q)=\left(\hat{\phi} D-\frac{q}{\theta}\right)^{+}$will encounter stockouts when they come to the store. Note that even though the inventory is $q$, up to $\frac{q}{\theta}$ customers may examine the product in the store because only a fraction $\theta$ of those customers will buy. Then, the retailer's profit is as follows:

$$
\begin{aligned}
\pi(q)= & p \theta E D_{\text {in }}(q)-c q \\
& +[w \theta-r(1-\theta)] E D_{\text {out }}(q) \\
& +[w \theta-r(1-\theta)](1-\hat{\phi}) E D
\end{aligned}
$$

Given the store inventory level $q$, the newsvendor expected profit from selling the product in the store channel is shown in the first term (1) above. The next two terms respectively represent profit from customers who switch online after encountering stockouts in the store and customers who buy online directly. For each unit of online demand, the expected profit is $w \theta-r(1-\theta)$, because a fraction $(1-\theta)$ of online sales are returned. Again, in the spirit of omnichannel retailing, we assume $w \theta-r(1-\theta)>0$ so that the retailer is willing to operate both channels. Finally, the retailer chooses inventory level $q$ to maximize expected profit.

To study the strategic interaction between the retailer and the consumers, we shall use the rational expectations (RE) equilibrium concept, which has been used in the literature on retail operations (see Su and Zhang (2008, 2009); Cachon and Swinney (2009)). One important feature of a RE equilibrium is that beliefs must be consistent with actual outcomes. In other words, the retailer's belief $\hat{\phi}$ must coincide with the true proportion $\phi$ of consumers choosing the store channel, and consumers' beliefs over in-store inventory availability $\hat{\xi}$ must agree with the actual in-stock probability corresponding to the retailer's chosen quantity $q$. This probability is given by $A(q)=E \min \left(\phi D, \frac{q}{\theta}\right) / E(\phi D)$, where $\phi>0$, using the derivation from Deneckere and Peck (1995) 
and Dana (2001). Then, we have the following definition for a RE equilibrium. Henceforth, we refer to the RE equilibrium as "equilibrium" for brevity.

Definition 1. A RE equilibrium $(\phi, q, \hat{\xi}, \hat{\phi})$ satisfies the following:

$i$ Given $\hat{\xi}$, if $u_{s}(\hat{\xi})>u_{o}$, then $\phi=1$; otherwise $\phi=0$;

ii. Given $\hat{\phi}, q=\arg \max _{q} \pi(q)$.

iii. $\hat{\xi}=A(q)$.

iv. $\hat{\phi}=\phi$.

Conditions (i) and (ii) state that under beliefs $\hat{\xi}$ and $\hat{\phi}$, the consumers and the retailer are choosing the optimal decisions. Conditions (iii) and (iv) are the consistency conditions.

First, note that there is always a nonparticipatory equilibrium $(0,0,0,0)$. If the retailer expects that no one will come to the store, he will stock nothing there, i.e., $q=0$; If consumers believe there is no inventory in the store, they will not come, i.e., $\phi=0$. In the end, we have a self-fulfilling prophecy and beliefs are trivially consistent with the actual outcome.

Is there any participatory equilibrium where consumers are willing to visit the store and the retailer has stock in the store as well (i.e., $\phi=1$ and $q>0$ )? When such an equilibrium exists, it Pareto-dominates the nonparticipatory equilibrium. The reasoning is as follows. In the participatory equilibrium, customers choose to visit the store rather than buying online directly (as what they would do in the nonparticipatory equilibrium), so they must be better off in the former. Similarly, the retailer prefers to stock $q>0$ in the participatory equilibrium rather than choosing $q=0$ (which leads customers to buy online and yields the same profit as the nonparticipatory equilibrium), so the retailer must also be better off in the participatory equilibrium. In this paper, we shall adopt the Pareto dominance equilibrium selection rule. The following proposition gives the equilibrium result; we use the superscript $\left({ }^{\circ}\right)$ to denote the equilibrium outcome for this base scenario. All proofs are presented in Supplementary Appendix I.

Proposition 1. There exists a threshold $\psi^{\circ} \in[0,1]$ such that

- if $\theta<\psi^{\circ}$, then consumers visit the store and $q^{\circ}=\theta \bar{F}^{-1}\left(\frac{c}{p-w+r \frac{1-\theta}{\theta}}\right)>0$;

- if $\theta \geq \psi^{\circ}$, then consumers buy online directly and $q^{\circ}=0$. 
Proposition 1 shows that consumers come to the store only if the high-type probability is low (i.e., $\theta<\psi^{\circ}$ ) and they recognize the need to touch and feel the product before making a purchase. In this case, the retailer prepares a positive amount of inventory in the store to accommodate consumer demand. To the retailer, the overage cost is simply the inventory cost $c$ and the underage cost is given by $p-c-w+r \frac{1-\theta}{\theta}$. The latter expression is the combination of two effects. First, each unit of underage is a lost opportunity of selling to a high type, who buys online instead, leading to a difference in profit margin of $p-c-w$. Second, each unit of underage is also a lost opportunity for customers to realize their valuations (by inspecting that unit of inventory); corresponding to one high type who could have bought this unit are $\frac{1-\theta}{\theta}$ low types who could have realized their low valuations and thus avoided the return cost $r$. Thus, as the online return cost $r$ increases, the retailer holds more inventory, purely for informational purposes.

\section{Physical Showrooms}

Previously, in the base model, consumers can evaluate the product in the store only if it is in stock. Now suppose that there is a physical showroom in the store, so that consumers can always inspect the product, even when it is out of stock. In this section, we study the equilibrium outcomes and profit implications of adding such a physical showroom.

As before, we start by considering the consumer's choice between shopping online and in store.

The consumer's payoff from visiting the store is $u_{s}(\hat{\xi})=-h_{s}+\hat{\xi} \theta(v-p)+(1-\hat{\xi}) \theta\left(v-p-h_{o}\right)$, given her belief about store inventory availability $\hat{\xi}$. Note that the first two parts of $u_{s}$ remain the same as in the base model. The only change occurs in the third term: when the consumer encounters stockouts in store, she is still able to realize her valuation from the physical showroom; she chooses to purchase online and receives payoff $v-p-h_{o}$ only if she is of high type. The consumer's payoff from buying online directly, on the other hand, remains unchanged as $u_{o}=\theta\left(v-p-h_{o}\right)-(1-\theta)\left(h_{o}+h_{r}\right)$.

The retailer has a belief $\hat{\phi}$ about the fraction of consumers who would visit the store. Given 
this belief, the retailer's profit is as follows.

$$
\begin{aligned}
\pi(q)= & p \theta E D_{\text {in }}(q)-c q \\
& +w \theta E D_{\text {out }}(q) \\
& +[w \theta-r(1-\theta)](1-\hat{\phi}) E D
\end{aligned}
$$

Comparing this to the profit function in the base model, we note that the only difference occurs in the term (5): this is because the physical showroom allows low types who encounter stockouts to learn their types and thus avoid the trouble of buying online and then returning. However, the two profit functions become identical when $r=0$. Nevertheless, the retailer may still obtain different profits in equilibrium because consumer channel choices may change after the implementation of physical showrooms (i.e., $\phi$ in equilibrium may be different), as shown below.

Similar to the analysis of the base model, we apply the notion of RE equilibrium to describe the market outcome. We use superscript.$^{p}$ to denote physical showrooms.

Proposition 2. With physical showrooms, there exists a threshold $\psi^{p} \in[0,1]$ such that

- if $\theta<\psi^{p}$, then consumers visit the store and $q^{p}=\theta \bar{F}^{-1}\left(\frac{c}{p-w}\right) \geq 0$;

- if $\theta \geq \psi^{p}$, then consumers buy online directly and $q^{p}=0$.

Moreover, $\psi^{p}>\psi^{\circ}$ if and only if $r \leq \bar{r}$ for some $\bar{r} \geq 0$.

Proposition 2 (after the provision of physical showrooms) differs from Proposition 1 (before the provision of physical showrooms) in two significant ways. First, with a physical showroom, it may be rational for consumers to visit the store even if they correctly expect that there is no inventory held in store. Specifically, note that when $p-c \leq w$ and $\theta<\psi^{p}$, the optimal store inventory is 0 but consumers still visit the store. In this case, the store serves as a pure showroom: Consumers can always evaluate their valuations in store, but they must make purchases online since there is no inventory in the store. The idea of pure showrooms has been pioneered by e-tailers such as Warby Parker and has proven to be effective in curbing high online return rates (Bell et al. 2015). It is not surprising that pure showrooms are mostly adopted by e-tailers (i.e., with $w$ higher than $p-c$ ); as these e-tailers establish a brick-and-mortar presence, they start holding inventory 
in the store. This is consistent with Warby Parker's recent move: in their stores, consumers can now buy non-prescription glasses and sunglasses to take with them.

Another difference between Propositions 1 and 2 is the change in store inventory level. Because low-type consumers will never buy online when the store is out of stock (since they can learn that they are of low type via the physical showroom), the underage cost decreases from $p-c-w+r \frac{1-\theta}{\theta}$ to $p-c-w$. As a consequence, the retailer holds less inventory in the store (i.e., $\left.q^{p} \leq q^{\circ}\right)$.

A reduction in store inventory level has a large impact on the channel choice of consumers. Consumers face two types of uncertainty during the shopping journey: (1) product value uncertainty, i.e., the possibility of buying something they do not like, and (2) availability uncertainty, i.e., the possibility of going to the store but encountering a stockout. By allowing consumers to inspect the product any time they come to the store, physical showrooms help to resolve product value uncertainty, which could attract consumers to visit the store; however, at the same time, the physical showrooms prompt the retailer to lower the store inventory level, which would increase availability risk and thus push consumers to the online channel. As a result, whether consumers are more likely to visit the store after physical showrooms are set up depends on which one of the two opposing effects is more significant. When returns are not too costly for the retailer (i.e., $r$ is small), the reduction of store inventory is small, so the first effect above dominates and physical showrooms attract some customers to the store (i.e., $\psi^{p}>\psi^{\circ}$ ). In contrast, when the return cost $r$ is very large, the second effect dominates and physical showrooms may drive consumers online (i.e., $\psi^{p}<\psi^{\circ}$ ). This consumer equilibrium behavior can be summarized in Figure 1.

Figure 1: Comparison of consumer behavior with and without physical showroom

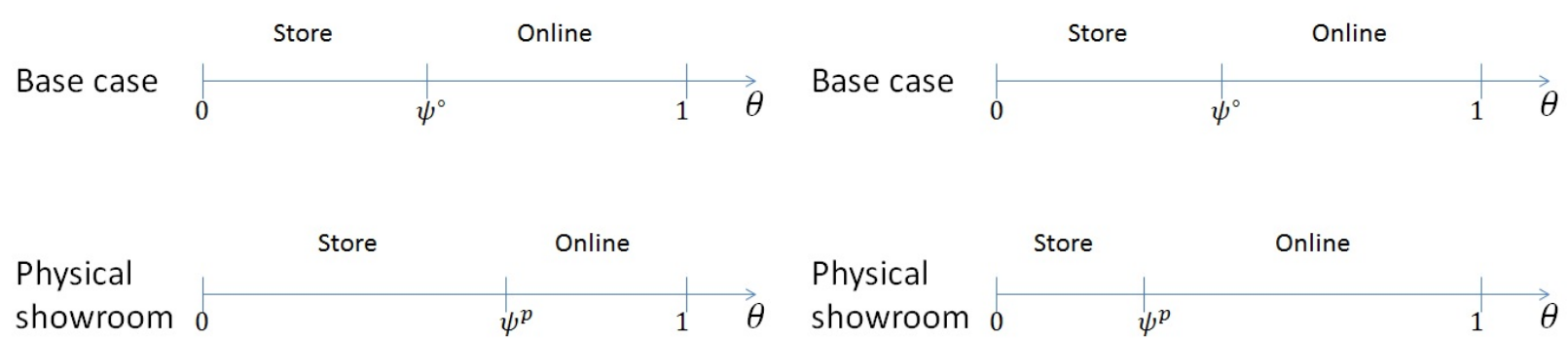

(a) If $r$ is small

(b) If $r$ is large

Proposition 3. Compared to base model,

- if $\theta<\psi^{p}$, then providing physical showrooms increases total profit (i.e., $\pi^{p}>\pi^{\circ}$ ); 
- if $\psi^{p}<\psi^{\circ}$ and $\theta \in\left[\psi^{p}, \psi^{\circ}\right)$, then providing physical showrooms reduces total profit (i.e., $\left.\pi^{p}<\pi^{\circ}\right)$

- if $\theta \geq \max \left(\psi^{p}, \psi^{\circ}\right)$, then providing physical showrooms generates the same amount of profit (i.e., $\left.\pi^{p}=\pi^{\circ}\right)$.

According to Proposition 3 , when the high-type probability is sufficiently large, i.e., $\theta \geq$ $\max \left(\psi^{p}, \psi^{\circ}\right)$, then the physical showroom does not make a difference since consumers will always purchase online. Offering a physical showroom is profitable to the retailer as long as customers actually visit the showroom in store (as when $\theta<\psi^{p}$ ). Note that in this case, if the store is out of stock, consumers simply check the product in store but eventually complete the purchase online. This shopping behavior is known as showrooming, but is generated by stockouts rather than price differences. Though consumer showrooming behavior has been critiqued widely because showroomers often end up buying from a competitor's website (Wall Street Journal, 2012a b), our result implies that it may still be beneficial to the retailer if consumers facing stockouts can be persuaded to make the purchase on the retailer's own online channel.

However, physical showrooms may have a negative effect on the retailer's profit when $\theta$ is moderate, i.e., $\theta \in\left[\psi^{p}, \psi^{\circ}\right)$. In this range, consumers would have come to the store in the base model, but now choose to buy online instead because they do not anticipate high in-stock probability in store. Then, the retailer would see an increase in returns and a decrease in profit; this is because the online purchases by low types will end up in returns. According to a comprehensive numerical study, the details of which are given in Supplementary Appendix III, the implementation of physical showrooms leads to a reduction in profit for about $4.34 \%$ of 914,895 different parameter combinations, most of which arise when the store profit margin $p-c$ is lower than the online profit $\operatorname{margin} w$.

\section{Virtual Showrooms}

Suppose the retailer implements virtual showrooms in the online channel. By trying on the product virtually, consumers receive an imperfect signal of their valuations. For modeling convenience, we assume that the signal $S$ is binary, i.e., a group of consumers remain interested in the product (i.e., $S=1$ ) while the remaining discover that the product is not for them and leave (i.e., $S=0$ ). Further, 
we assume that the latter group consists of a fraction $\alpha \in(0,1]$ of the low-type customers, i.e., the probabilities that a low-type and a high-type customer receives a signal $S=0$ are $P(S=0 \mid L)=\alpha$ and $P(S=0 \mid H)=0$, respectively, where $L$ and $H$ denotes the consumer type (i.e., low and $h$ igh). In other words, the virtual showroom only screens out some of low-type customers, while potential high-type customers still have interest in the product after trying the product virtually. Note if $\alpha=1$, the virtual showroom offers a perfect signal and all consumers learn their types, but if $\alpha<1$, the virtual showroom screens out a fraction $\alpha$ of the low types. We thus interpret $\alpha$ as the degree of informativeness of the virtual showroom.

We apply Bayesian updating to the beliefs of those consumers who remain interested in the product. This group includes all potential high-type customers and a fraction $1-\alpha$ of the potential low-type customers. Let $\theta^{\prime}$ denote the posterior probability of a remaining customer (i.e., those who received signal $S=1$ ) being high-type. Then, given the priors $P(H)=\theta$ and $P(L)=1-\theta$, we have $\theta^{\prime}=P(H \mid S=1)=\frac{P(S=1 \mid H) P(H)}{P(S=1 \mid H) P(H)+P(S=1 \mid L) P(L)}=\frac{\theta}{1-\alpha(1-\theta)}>\theta$. Then, the two models, with and without virtual showrooms, are very similar. The only difference is that virtual showrooms generate a new consumer pool by filtering away some potential low-type consumers. As a result, the total demand size is $D^{\prime}=P(S=1) D=[1-\alpha(1-\theta)] D\left(\right.$ with $\operatorname{cdf} F^{\prime}(x)=F\left(\frac{x}{1-\alpha(1-\theta)}\right)$ for any $x$ ) and a fraction $\theta^{\prime}$ of them is of high type. Thus, similar to Proposition 1 , the equilibrium outcome is given in the following proposition; we use the superscript $\left(\cdot{ }^{v}\right)$ to denote the equilibrium outcome for the scenario with virtual showrooms. Henceforth, without further specification, we simply refer to this new pool of consumers as the retailer's consumers.

Proposition 4. With virtual showrooms, there exists a threshold $\psi^{v} \in\left[0, \psi^{\circ}\right]$ such that

- if $\theta<\psi^{v}$, then consumers visit the store and $q^{v}=\theta^{\prime} \bar{F}^{\prime}-1\left(\frac{c}{p-w+r \frac{1-\theta^{\prime}}{\theta^{\prime}}}\right)>0$;

- if $\theta \geq \psi^{v}$, then consumers buy online directly and $q^{v}=0$.

Comparing Proposition 4 (after the provision of virtual showrooms) and Proposition 1 (before the provision of virtual showrooms), since $\psi^{v} \leq \psi^{\circ}$, virtual showrooms may attract customers to buy online instead of in the store (see Figure 2). This is not surprising. Virtual showrooms give consumers a similar hands-on experience as in the store. With decreased product value uncertainty, shopping online becomes more productive and appealing to consumers.

Interestingly, virtual showrooms are similar to consumer reviews; both provide online consumers with product information to help them alleviate value uncertainty. However, while reviews 
Figure 2: Comparison of consumer behavior with and without virtual showroom

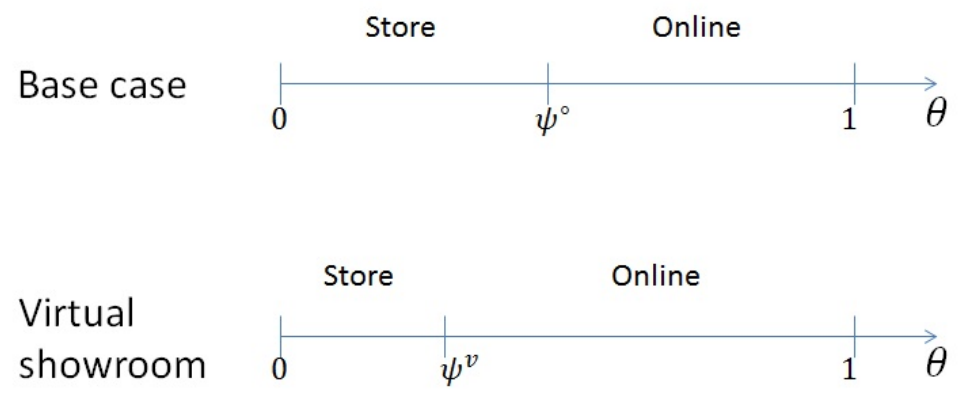

provide subjective information from other consumers, virtual showrooms provide objective information from the retailer. Therefore, consumer reviews may be subject to self-selection biases, e.g., Li and Hitt (2008), and they can also be influenced through dynamic pricing, as in Papanastasiou and Savva (2014); Yu et al. (2015). In contrast, virtual showrooms offer information content that is immune to strategic manipulation.

Proposition 5. Compared to the base model,

- if $\theta<\psi^{v}$ or $\theta \geq \psi^{\circ}$, then providing virtual showrooms increases total profit, i.e., $\pi^{v}>\pi^{\circ}$;

- if $\theta \in\left[\psi^{v}, \psi^{\circ}\right)$, there exists $\bar{w}$ such that providing virtual showrooms increases total profit (i.e., $\pi^{v}>\pi^{\circ}$ ) if $w>\bar{w}$; but reduces total profit (i.e., $\pi^{v}<\pi^{\circ}$ ) if $w<\bar{w}$.

There are three cases discussed in Proposition 5 . First, if consumers have a small hightype probability (i.e., $\theta<\psi^{v}$ ), then they always turn to the physical store for validation before making any purchasing decision. When the store is out of stock, consumers may choose to buy online directly before resolving product value uncertainty. In this case, virtual showrooms help by screening out some low-type consumers beforehand so that the potential number of returns will be smaller.

Second, if consumers have a large high-type probability (i.e., $\theta \geq \psi^{\circ}$ ), then they are comfortable buying online. In this case, virtual showrooms serve as the main source of product information for consumers. By screening out potential low-type customers before they make any purchase on the website, virtual showrooms help to avoid returns and increase profits.

However, when $\theta \in\left[\psi^{v}, \psi^{\circ}\right)$, implementing virtual showrooms may backfire. In this case, consumers originally visit the store in the base model, but virtual showrooms attract them to buy 
online instead. Although the online return rate decreases from $1-\theta$ (without virtual showroom) to $1-\theta^{\prime}$ (with virtual showroom), total returns may increase. This is because more people now choose to buy online, including low types who are destined to return their purchases. The resulting increase in returns will drive down total profit. Unless the online profit margin is high enough, customer migration from store to online will be unprofitable for the retailer. This result offers a possible explanation for fashion retailer H\&M's decision to remove their virtual showroom (called the Dressing Room) from their website even though it has been popular among consumers (H\&M) 2010). Our result also suggests that retailers should be cautious when looking at online return rates and should not neglect the total number of returns as an informative companion metric. According to a comprehensive numerical study, the details of which are given in Supplementary Appendix III, the implementation of virtual showrooms hurts profits for about $4.58 \%$ of 914,895 different parameter combinations, most of which arise when the online profit margin $w$ is lower than the store profit margin $p-c$.

\section{Availability Information}

Suppose the retailer provides availability information on its website, so that consumers are able to check real-time store inventory status. With such information, the sequence of consumer arrivals matter: consumers who arrive early will see that the store is in stock, but consumers who arrive late will encounter stockouts. In the former case, the consumer can go to the store and receive an expected payoff of $u_{s, i n}=-h_{s}+\theta(v-p)$ because she will certainly obtain the product if she realizes high valuation. In the latter case, the consumer will receive nothing from visiting the store and thus will choose to buy online instead. In practice, some retailers may also reveal the number of units in inventory as part of the availability information. This does not change consumers' shopping behavior in our model, since consumers care only about whether the store is in stock or not when they arrive in the market.

Each consumer chooses between shopping online directly or going to the store, given the current store inventory availability status. Let $\phi_{i n}$ denote the fraction of customers visiting the store when it is in stock. As before, only high-type consumers will absorb store inventory when they come to the store. Then, the expected number of customers who see that the store is in stock

is $D_{\text {in }}(q)=\min \left(D, \frac{q}{\theta \phi_{i n}}\right)$, and the remaining $D_{\text {out }}(q)=\left(D-\frac{q}{\theta \phi_{i n}}\right)^{+}$will find that the store is 
already out of stock when they check availability online. Note that the expressions for $D_{i n}(q)$ and $D_{\text {out }}(q)$ are slightly different from before because all consumers, whether they choose to come to the store, will receive availability information. Thus, the retailer's profit function is as follows:

$$
\begin{aligned}
\pi(q)= & p \theta \phi_{\text {in }} E D_{\text {in }}(q)-c q \\
& +[w \theta-r(1-\theta)]\left(1-\phi_{\text {in }}\right) E D_{\text {in }}(q) \\
& +[w \theta-r(1-\theta)] E D_{\text {out }}(q)
\end{aligned}
$$

The first two parts of the profit function correspond to the case when the store is in stock: (7) is the newsvendor profit from the store, and (8) is the profit from those who buy online directly. The last part (9) corresponds to the case when the store is out of stock and all consumers buy online.

We use superscript $\left({ }^{a}\right)$ to denote the market outcome with availability information, which is given in the following proposition.

Proposition 6. With availability information, there exists a threshold $\psi^{a} \in\left[\psi^{\circ}, 1\right]$ such that the market outcome is given as follows:

- If $\theta<\psi^{a}$, then consumers visit store if store is in stock, and buy online directly if store is out of stock; $q^{a}=\theta \bar{F}^{-1}\left(\frac{c}{p-w+r \frac{1-\theta}{\theta}}\right)>0$

- If $\theta \geq \psi^{a}$, then consumers always buy online directly; $q^{a}=0$.

Comparing Proposition 6 (after the provision of availability information) and Proposition 1 (before the provision of availability information), since $\psi^{a} \geq \psi^{\circ}$, we see that providing availability information may attract consumers to the store (see Figure 3). In the base scenario, consumers bear availability risk because they incur the hassle of going to the store before finding out whether the store is in stock. Now, providing availability information eliminates availability risk: if the store is in stock, consumers are guaranteed availability before incurring any sunk cost.

Su and Zhang (2009) study a different availability information sharing mechanism, i.e., quantity commitment, under which the retailer commits to an initial inventory level in the store. Note there are two key differences between quantity commitment and the availability information mechanism studied in our paper. First, quantity commitment merely informs consumers about the retailer's initial inventory level, and thus consumers may still encounter stockouts when they visit 
Figure 3: Comparison of consumer behavior with and without availability information
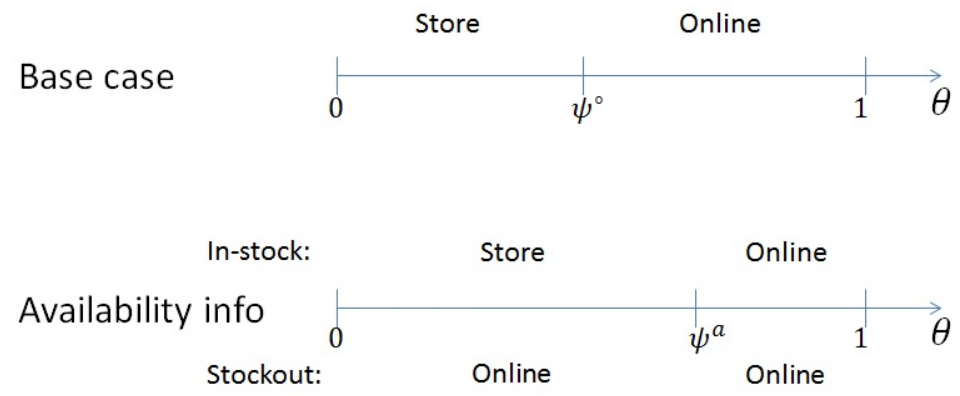

the store; in contrast, with real-time availability information, consumers no longer need to face any availability uncertainty. Second, as the name suggests, quantity commitment requires a commitment device (e.g., reputation or legal institutions), but real-time availability information is easily verifiable (e.g., using mobile devices); in this sense, the latter is simpler to implement.

Proposition 7. Compared to the base model,

- if $\theta<\psi^{\circ}$ or $\theta \geq \psi^{a}$, then providing availability information generates the same amount of profit, i.e., $\pi^{a}=\pi^{\circ}$;

- if $\theta \in\left[\psi^{\circ}, \psi^{a}\right)$, then providing availability information increases total profit, i.e., $\pi^{a}>\pi^{\circ}$.

According to Proposition 7, offering availability information has no negative effect on the retailer. Specifically, if availability risk is not a pivotal factor in consumers' shopping decision, e.g., they always visit the store because of high product value uncertainty (as when $\theta \leq \psi^{\circ}$ ) or they always feel comfortable buying online directly (as when $\theta>\psi^{a}$ ), then sharing availability information with consumers does not make a difference.

In contrast, if consumers care about availability risk and choose to buy online purely out of concern for such risk (as when $\theta \in\left[\psi^{\circ}, \psi^{a}\right)$ ), then providing availability information will have a positive effect on profits. By assuring consumers about inventory availability in store, the retailer can attract more people to the store; consumers can then physically inspect the product and realize their valuation before making any purchase. The bottom-line is a decrease in product returns and thus an increase in total profit. 


\section{Joint Implementation}

So far, we have separately looked at physical showrooms, virtual showrooms, and availability information. For each information mechanism, we have studied the individual impact on consumer behavior and retail operational efficiency. In this section, we focus on the interactions among them, searching for potential complementary effects when the retailer implements more than one of them at the same time. The goal of this section is to find out what combination of the three mechanisms the retailer should implement. In the following analysis, we combine the superscripts of corresponding types of information mechanisms to form the notation for the combined scenario. For example, superscript .pa denotes the case where both physical showroom and availability information are provided. We start with pairwise combinations before considering implementing all three mechanisms simultaneously. Detailed analyses of the market outcome of all these scenarios are given in Appendix A.

We start with combining physical showrooms and availability information.

Proposition 8. $\pi^{p a} \leq \max \left(\pi^{p}, \pi^{a}\right)$, and there exists $\underline{\psi}^{p a} \in\left[0, \psi^{p}\right]$ such that $\pi^{p a}<\pi^{p}$ if $\theta \in$ $\left[\underline{\psi}^{p a}, \psi^{p}\right)$.

According to Propositions 2 and 6, both physical showroom and availability information attract customers to the store. It is this overlap that creates redundancy if they are implemented together. As shown in Proposition 8, there is no complementary effect between these two mechanisms. In fact, offering availability information may hurt profits if the retailer has already implemented physical showrooms. We provide a brief explanation next.

When there are both physical showrooms and availability information, as shown in Appendix A.1. consumers always visit the store when the high-type probability is small (i.e., $\theta<\underline{\psi}^{p a}$ ), even when the store is already out of stock and consumers know that. In such cases, consumers still prefer to check the product in the physical showroom before making any purchase. However, if the high-type probability is slightly higher, then consumers would stop coming to store and instead choose to buy online directly once they know that the store is out of stock. As a result, the retailer can no longer use the physical showroom to screen out potential low-type consumers; this may lead to more returns and less profit.

Next, let us combine physical showrooms and virtual showrooms. 
Proposition 9. $\pi^{p v} \leq \max \left(\pi^{p}, \pi^{v}\right)$, and there exists $\psi^{p v} \in\left[0, \psi^{p}\right]$ such that (1) $\pi^{p v}<\pi^{p}$ if $\theta \in\left[\psi^{p v}, \psi^{p}\right)$, and (2) $\pi^{p v}<\pi^{v}$ if $\psi^{p v}<\psi^{v}$ and $\theta \in\left[\psi^{p v}, \psi^{v}\right)$.

Both types of showrooms help consumers alleviate product value uncertainty. Given this overlap, Proposition 9 points out that it is sufficient to implement only one of them. Again, we see that a profit loss may result when both types of showrooms are used together compared to the case when they are implemented individually.

The reason why offering both showrooms would make profit strictly worse is because each one of them may bring about some negative effects as discussed in previous sections, and combining both does not help to solve these issues. Specifically, when $\theta \in\left[\psi^{p v}, \psi^{p}\right)$, compared to the case where there is only physical showrooms, similar to what we have found in Proposition 5, adding virtual showrooms would cause consumers (including some low types) to buy online instead of in store, and thus there will be more returns. When $\psi^{p v}<\psi^{v}$ and $\theta \in\left[\psi^{p v}, \psi^{v}\right)$, compared to the case where there is only virtual showroom, similar to what we have found in Proposition 3 , adding physical showrooms may prompt the retailer to decrease store inventory so much that consumers choose to buy online without first resolving their product value uncertainty in the store.

Finally, we consider the remaining combinations of: (i) putting together virtual showrooms and availability information, and (ii) putting together all three information mechanisms. These are respectively studied in the two parts of the following proposition.

\section{Proposition 10.}

- There exists $\psi^{v a} \in\left[\psi^{v}, 1\right]$ such that $\pi^{v a}>\max \left(\pi^{v}, \pi^{a}\right)$ if $\theta \in\left[\psi^{v}, \psi^{v a}\right)$;

- $\pi^{p v a} \leq \max \left(\pi^{p v}, \pi^{v a}\right)$, and there exists $\underline{\psi}^{p v a} \in\left[0, \psi^{p v}\right]$ such that $\pi^{p v a}<\pi^{p v}$ if $\theta \in\left[\underline{\psi}^{p v a}, \psi^{p v}\right)$.

Proposition 10 contains two parts. The first part shows that there may be a complementary effect between virtual showrooms and availability information. This happens if $\theta \in\left[\psi^{v}, \psi^{v a}\right)$, i.e., consumers visit the store when it is in stock and buy online if the store is out of stock (see Proposition A.3.1 in Appendix A.3. In this case, the synergy between availability information and virtual showrooms works as follows: availability information helps to attract consumers to the store by eliminating availability uncertainty, and when the store is out of stock and consumers buy online, the virtual showroom serves as a filter to screen out low-type consumers. Out of the three information mechanisms studied in this paper, virtual showrooms and availability information 
is the only pair that exhibits complementarity. This is because there are potential overlaps in the functions of these mechanisms: Both physical showrooms and availability information would attract customers to store, while both physical and virtual showrooms would mitigate consumers' product value uncertainty. Consequently, it is unsurprising that we find complementary effects only between virtual showrooms and availability information. In the same spirit, we also find that it is not necessary to combine all three different types of information mechanisms, as shown in the second part of Proposition 10 .

To conclude this section, we examine the optimal information structure, based on the three mechanisms that we have studied. Since it may be costly to implement any one of them, we consider offering multiple mechanisms only when it generates strictly higher profit. Then, given Propositions 8 -10, there are five possible options: choose exactly one of the three mechanisms, implement both virtual showrooms and availability information, or "do nothing" as in the base model. Let $\pi^{*}$ denote the optimal profit under the optimal information structure. We have the following result.

\section{Proposition 11.}

i. If $\theta<\psi^{p}$, then $\pi^{*}=\pi^{p}$;

ii. If $\theta \geq \psi^{p}$, then

a) if customers visit the store in the base model (i.e., $\theta<\psi^{\circ}$ ), then there exist thresholds $\alpha_{1}, \alpha_{2}, \alpha_{3} \in[0,1]$ such that $\alpha_{1} \leq \alpha_{2} \leq \alpha_{3}$ and

$*$ if $\alpha<\alpha_{1}$, then $\pi^{*}=\pi^{v}$

* if $\alpha \in\left(\alpha_{1}, \alpha_{2}\right)$, then $\pi^{*}=\pi^{v a}$

* if $\alpha \in\left(\alpha_{2}, \alpha_{3}\right)$, then $\pi^{*}=\pi^{\circ}$

* if $\alpha>\alpha_{3}$, then $\pi^{*}=\pi^{v}$

b) if customers buy online in the base model (i.e., $\theta \geq \psi^{\circ}$ ), then there exist thresholds $\alpha_{1}^{\prime}, \alpha_{2}^{\prime} \in[0,1]$ such that $\alpha_{1}^{\prime} \leq \alpha_{2}^{\prime}$ and

* if $\alpha<\alpha_{1}^{\prime}$, then $\pi^{*}=\pi^{v a}$

* if $\alpha \in\left(\alpha_{1}^{\prime}, \alpha_{2}^{\prime}\right)$, then $\pi^{*}=\pi^{a}$

* if $\alpha>\alpha_{2}^{\prime}$, then $\pi^{*}=\pi^{v}$ 
Proposition 11 suggests that the main driver behind the optimal information mechanism is the parameter $\theta$, i.e., the high-type probability. Part (i) of the proposition shows that when $\theta$ is low (i.e., $\theta<\psi^{p}$ ), it is optimal to provide only physical showrooms; part (ii) shows that when $\theta$ is high (i.e., $\left.\theta \geq \psi^{p}\right)$, virtual showrooms or/and availability information work better. A reasonable proxy for the $\theta$ parameter is the online return rate, since products with a smaller high-type probability $\theta$ are more likely to be returned. Therefore, Proposition 11(i) suggests that for products that are traditionally afflicted with high online return rates (e.g., fashion apparel and accessories), physical showrooms should be implemented to attract customers into stores to touch and feel the product before making a purchase. Our analysis advocates physical showrooms rather than virtual showrooms, which tend to be a more intuitive choice for retailers plagued by online returns. Our finding is also consistent with the recent move by many fashion retailers' (e.g., Bonobos and Warby Parker's) to build more physical showrooms (New York Times, 2014; Wall Street Journal, 2014).

Next, for products with relatively more manageable online return rates, such as home goods and electronics (Laseter and Rabinovich, 2011, pg.118), Proposition 11(ii) describes the optimal information mechanism. Depending on whether customers visit the store or buy online directly in the base model (i.e., without any information mechanism), the baseline scenarios are different and our results are separately reported in parts (ii)(a) and (ii)(b). In both cases, our results suggest that the retailer should consider implementing virtual showrooms to provide product value information to consumers, and possibly also provide availability information to maintain the attractiveness of the store channel. In part (ii)(a), we also find that when customers visit the store in the base model, it may be optimal to not implement any additional information mechanism at all.

Proposition 11 also demonstrates the importance of the $\alpha$ parameter, i.e., the informativeness of the virtual showroom. Some implementations of virtual showrooms involve relatively rudimentary functions (e.g., picture upload), while others use more advanced virtual reality technologies (e.g., 3D technology) which offer online shoppers a more vivid try-on experience. As virtual showrooms become more informative (i.e., as $\alpha$ increases), Proposition 11(ii) shows that it is possible for them to become less attractive. Specifically, in both parts (a) and (b), virtual showrooms are a part of the optimal information mechanism only when $\alpha$ is either sufficiently large or sufficiently small. In other words, attempts to enhance the informativeness of virtual showrooms, if not significant, may reduce profits. The reason is as follows: unless the virtual showroom becomes very effective in screening out low-type customers, it may simply end up attracting online transactions and thus 
increasing online returns.

\section{Extensions}

\subsection{Endogenous Online Channel}

In our original model, we have assumed that the online channel is exogenous; specifically, there is always enough inventory to satisfy online demand. We can extend our basic model to include an endogenous online channel as follows. Suppose the retailer has a one-time ordering opportunity to prepare the inventory level $q_{s}$ and $q_{o}$ in the store and online channel. The unit inventory costs in the store and online channels are $c_{s}$ and $c_{o}$, respectively. The product price $p$ is still the same across both channels. Then, for each unit of product sold online, if it is not returned, the retailer earns the revenue $p$; if it is returned, the retailer incurs a net cost $k$. When the store is out of stock, consumers may switch back to the retailer's online channel as before. When the online channel is out of stock, those who are willing to buy online will leave for other websites to buy the product at the same price. In many companies (e.g., Bonobos and Warby Parker), store employees are trained and equipped with digital devices to help store customers order online. However, when customers are shopping online at home, it is hard for a firm to persuade customers to come to store when online is out of stock. Our model setup is to capture this difference. Gao and Su (2016) use a similar assumption to study a specific omnichannel fulfillment strategy, i.e., buy-online-and-pickupin-store. Supplementary Appendix II1 presents a detailed analysis of this model. We find that the drivers behind consumer channel choice and the effects of the three information mechanisms remain unchanged.

\subsection{Continuous Valuations}

Our analysis has assumed that consumer valuation can take on only two values, either $v$ or 0 . As a result, there are only two types of customer in the market, i.e., high types (who like the product) and low types (who don't). Our model can be extended to a more general case. Suppose consumer valuation $V$ follows a continuous distribution $G$. Similar as our basic model, consumers are homogeneous ex ante; they know the distribution $G$ but not their individual valuation beforehand.

Consumers who buy online directly will realize their valuations after receiving the delivery, 
and there are three possible outcomes. Consumers with $V>p$ will find that they like the product and thus keep it, and consumers with $V<p-h_{r}$ will find that they do not like the product and thus return it. These two types of behavior correspond to the high type and low type in the basic model. Finally, we have a third possibility: consumers with $V \in\left(p-h_{r}, p\right)$ will find that they do not like the product (since $V-p<0$ ) but they still choose to keep it rather than going through the hassles of returning it back to the retailer ( since $\left.-h_{r}<V-p\right)$.

When there is a virtual showroom, similar as in the basic model, we assume that it helps to screen out some "low-type" customers in the online channel. Specifically, the signal consumers receive after checking with the virtual showroom is binary: those with valuation $V<\bar{v}$ will realize that their valuation is low and therefore leave the market without any purchase, while those with valuation $V \geq \bar{v}$ will realize that their valuation is greater than $\bar{v}$ and update their belief about the valuation distribution to $G^{\prime}$ such that $\forall v \geq \bar{v}, G^{\prime}(v)=\frac{G(v)-G(\bar{v})}{1-G(\bar{v})}$, where the threshold $\bar{v} \leq p-h_{r}$. With some "low-type" customers being screened out, the total number of customers left in the market is $D^{\prime}=[1-G(\bar{v})] D$. Then, we obtain a new customer pool with total demand size $D^{\prime}$ and valuation distribution $G^{\prime}$. A detailed analysis of this model extension is given in Supplementary Appendix II2, from which we find that our main insights remain valid.

\subsection{Informed and Uninformed Consumers}

So far, we have assumed that consumers are homogeneous at the beginning of their shopping journey, although they may have different realized valuations ex post. We can extend our basic model to incorporate ex ante heterogeneity in the consumer population. Specifically, suppose that a fraction $\lambda$ of the customers are informed, i.e., they know that they are of high type (i.e., with valuation $v$ ) right from the beginning. The remaining fraction $1-\lambda$ of customers are uninformed as before, i.e., they do not know their types but they know the high-type probability $\theta$. As a result, only uninformed customers will react to the implementation of physical/virtual showrooms, since informed customers do not need any product value information.

Supplementary Appendix II3 presents a detailed analysis of our extended model, which shows that most of our key insights continue to hold. However, there is a slight difference: specifically, we find that the retailer may sometimes wish to offer both physical showrooms and availability information (because the former caters to uninformed customers while the latter caters to informed 
customers). Nevertheless, we continue to find that physical and virtual showrooms do not exhibit any complementary effects.

\subsection{Heterogeneous Valuations}

In our analysis, we have assumed that customers have the same valuation $v$ if they find they like the product. Our model can also be extended to the case where consumers have heterogeneous valuations. Suppose there are two types of customers and a fraction $\theta$ of the first (second) type customers has value $v_{1}\left(v_{2}\right)$, and a fraction $1-\theta$ has zero value. Then, as long as both types of customers are willing to consider both channels, i.e., $u_{s i}(1) \geq 0$ and $u_{o i} \geq 0, i=1,2$, all of our previous results continue to hold. The reason is as follows: Each consumer's channel choice (which is determined by the sign of $u_{s i}-u_{o i}$ ) is independent of their valuation. Also, because customers pay the same price and they have the same probability $1-\theta$ of returning the product, the retailer obtains the same expected profit from each type of customers. In other words, from the retailer's perspective, the two types of customer are the same.

\section{Conclusion}

Consumers are no longer dedicated to one particular channel. Their shopping journey has become omnichannel; they strategically switch channels to best suit their personal convenience when evaluating and purchasing products. In response, more and more retailers are starting to transition from the traditional channel-specific management style to omnichannel operations, where different channels are integrated in a seamless way. In this paper, we studied three omnichannel information mechanisms, i.e., physical showrooms, virtual showrooms, and availability information, which have been recently experimented and adopted by an increasing number of retailers.

The implementation of any omnichannel strategy is not easy. For example, to set up physical showrooms, a retailer may need to restructure its stores; similarly, virtual showrooms rely on the development of relevant technologies, and an integrated information system is needed to provide availability information online. However, we believe that these technical barriers will eventually be overcome. In this paper, we have put aside considerations of implementation cost, and set our focus on the implications of these information mechanisms on retail operations. This way, we hope 
to help retailers understand the pros and cons if and when implementation becomes possible.

In this paper, we build a stylized model that captures essential elements of omnichannel retail environments. We find the information mechanisms are generally profitable to a retailer by helping to alleviate consumer uncertainty about product value and inventory availability. However, in some cases, we find unexpected consequences that lead to more returns and less profit, echoing the well-known enigma that providing more information does not necessarily translate into higher profits. Furthermore, we find that the information mechanisms studied herein may be substitutes, so retailers should exercise caution when implementing multiple mechanisms simultaneously.

The current model focuses on a retailer's inventory decision, while price is assumed to be exogenous. This model setup applies to the case where the price is predetermined. For example, Warby Parker has kept the price of most of their glasses constant at $\$ 95$, even after they have implemented showrooms. Another interesting and important question is how to integrate omnichannel initiatives with pricing strategies. Price differentiation has generated the phenomenon of showrooming: shoppers physically inspect a product in one retailer's store and then buy the same product from another online retailer at a lower price (Wall Street Journal, 2012a b). Balakrishnan et al. (2014); Mehra et al. (2013) provide some initial analyses in this area. When consumers engage in showrooming, one might expect that physical showrooms will become less profitable; however, there is anecdotal evidence suggesting that big-box retailers, the presumed victims of showrooming behavior, are in fact trying to make their stores a better showroom for consumers (CNBC, 2013 , Wall Street Journal, 2013a). Future research is needed to understand this interesting phenomenon.

\section{Acknowledgements}

The authors are grateful to Gerard Cachon, Morris Cohen and Lorin Hitt for helpful discussions. They also appreciate the feedback from participants at INFORMS and POMS conferences. The authors also thank the editors and reviewers for their constructive suggestions, which have significantly improved the paper. Financial support from the Baker Retailing Center is gratefully acknowledged. 


\section{References}

Akçay, Y., T. Boyacı, and D. Zhang (2013). Selling with money-back guarantees: The impact on prices, quantities, and retail profitability. Production and Operations Management 22(4), 777-791.

Alexandrov, A. and M. A. Lariviere (2012). Are reservations recommended? Manufacturing $\&$ Service Operations Management 14(2), 218-230.

Allon, G. and A. Bassamboo (2011). Buying from the babbling retailer? The impact of availability information on customer behavior. Management Science 57(4), 713-726.

Altug, M. S. and T. Aydinliyim (2015). Counteracting strategic purchase deferrals: The impact of online retailers' return policy decisions. Working paper, George Washington University.

Aviv, Y. and A. Pazgal (2008). Optimal pricing of seasonal products in the presence of forwardlooking consumers. Manufacturing \&5 Service Operations Management 10(3), 339-359.

Balakrishnan, A., S. Sundaresan, and B. Zhang (2014). Browse-and-switch: Retail-online competition under value uncertainty. Production and Operations Management 23(7), 1129-1145.

Bell, D., S. Gallino, and A. Moreno (2014). How to win in an omnichannel world. MIT Sloan Management Review 56(1).

Bell, D., S. Gallino, and A. Moreno (2015). Offline showrooms and customer migration in omnichannel retail. Working paper, University of Pennsylvania.

Besbes, O. and I. Lobel (2015). Intertemporal price discrimination: Structure and computation of optimal policies. Management Science 61(1), 92-110.

Brynjolfsson, E., Y. J. Hu, and M. S. Rahman (2013). Competing in the age of omnichannel retailing. MIT Sloan Management Review 54(4), 23-29.

Cachon, G. P. and P. Feldman (2015). Price commitments with strategic consumers: Why it can be optimal to discount more frequently than optimal. Manufacturing $\&$ Service Operations Management.

Cachon, G. P. and R. Swinney (2009). Purchasing, pricing, and quick response in the presence of strategic consumers. Management Science 55(3), 497-511. 
Cattani, K., W. Gilland, H. S. Heese, and J. Swaminathan (2006). Boiling frogs: Pricing strategies for a manufacturer adding a direct channel that competes with the traditional channel. Production and Operations Management 15(1), 40-56.

Che, Y.-K. (1996). Customer return policies for experience goods. The Journal of Industrial Economics, 17-24.

Chen, K.-Y., M. Kaya, and Ö. Özer (2008). Dual sales channel management with service competition. Manufacturing \& Service Operations Management 10(4), 654-675.

Chiang, W.-y. K., D. Chhajed, and J. D. Hess (2003). Direct marketing, indirect profits: A strategic analysis of dual-channel supply-chain design. Management Science 49(1), 1-20.

CNBC (2013, November). It's game on for a retooled best buy this holiday season.

CNBC (2015, April). Retail's new reality: Invisible shopping centers and virtual assistants.

CNET (2010, May). Shoefitr uses 3D to help buy the right kicks.

Dana, J. D. (2001). Competition in price and availability when availability is unobservable. Rand Journal of Economics, 497-513.

Dana, J. D. and N. C. Petruzzi (2001). Note: The newsvendor model with endogenous demand. Management Science 47(11), 1488-1497.

Davis, S., E. Gerstner, and M. Hagerty (1995). Money back guarantees in retailing: Matching products to consumer tastes. Journal of Retailing 71(1), 7-22.

Davis, S., M. Hagerty, and E. Gerstner (1998). Return policies and the optimal level of "hassle". Journal of Economics and Business 50(5), 445-460.

Deneckere, R. and J. Peck (1995). Competition over price and service rate when demand is stochastic: A strategic analysis. The RAND Journal of Economics, 148-162.

Financial Times (2011, January). Next big trend: virtual fitting rooms.

Forrester (2014). Customer desires vs. retailer capabilities: Minding the omni-channel commerce gap. Technical report, Forrester Consulting.

Gallego, G. and Ö. Sahin (2010). Revenue management with partially refundable fares. Operations Research 58(4-part-1), 817-833. 
Gallino, S. and A. Moreno (2014). Integration of online and offline channels in retail: The impact of sharing reliable inventory availability information. Management Science 60(6), 1434-1451.

Gallino, S., A. Moreno, and I. Stamatopoulos (2014). Channel integration, sales dispersion, and inventory management. Working paper, Dartmouth College.

Gao, F. and X. Su (2016). Omnichannel retail operations with buy-online-and-pickup-in-store. Management Science, Forthcoming.

H\&M (2010). H\&M annual report 2010.

Hsiao, L. and Y.-J. Chen (2012). Returns policy and quality risk in e-business. Production and Operations Management 21(3), 489-503.

Jerath, K., S. Netessine, and S. K. Veeraraghavan (2010). Revenue management with strategic customers: Last-minute selling and opaque selling. Management Science 56(3), 430-448.

Laseter, T. M. and E. Rabinovich (2011). Internet retail operations: integrating theory and practice for managers. CRC Press.

Levin, Y., J. McGill, and M. Nediak (2009). Dynamic pricing in the presence of strategic consumers and oligopolistic competition. Management science 55(1), 32-46.

Li, X. and L. M. Hitt (2008). Self-selection and information role of online product reviews. Information Systems Research 19(4), 456-474.

Liang, C., M. Cakanyildirim, and S. P. Sethi (2014). Analysis of product rollover strategies in the presence of strategic customers. Management Science 60(4), 1033-1056.

Liu, Q. and G. J. van Ryzin (2008). Strategic capacity rationing to induce early purchases. Management Science 54(6), 1115-1131.

Lobel, I., J. Patel, G. Vulcano, and J. Zhang (2014). Optimizing product launches in the presence of strategic consumers. Working paper, New York University.

Mehra, A., S. Kumar, and J. S. Raju (2013). "Showrooming" and the competition between store and online retailers. Working paper, Unversity of Pennsylvania.

Mersereau, A. J. and D. Zhang (2012). Markdown pricing with unknown fraction of strategic customers. Manufacturing \&5 Service Operations Management 14(3), 355-370. 
Moorthy, S. and K. Srinivasan (1995). Signaling quality with a money-back guarantee: The role of transaction costs. Marketing Science 14(4), 442-466.

Netessine, S. and N. Rudi (2006). Supply chain choice on the internet. Management Science 52(6), $844-864$.

New York Times (2014, July). For Bonobos, a good fit in stores as well as online.

Osadchiy, N. and G. Vulcano (2010). Selling with binding reservations in the presence of strategic consumers. Management Science 56(12), 2173-2190.

Papanastasiou, Y. and N. Savva (2014). Dynamic pricing in the presence of social learning and strategic consumers. Working paper, London Business School.

Rigby, D. (2011). The future of shopping. Harvard Business Review 89(12), 65-76.

$\mathrm{Su}, \mathrm{X}$. (2007). Intertemporal pricing with strategic customer behavior. Management Science 53(5), $726-741$.

Su, X. (2009). Consumer Returns Policies and Supply Chain Performance. Manufacturing Es Service Operations Management 11(4), 595-612.

Su, X. and F. Zhang (2008). Strategic customer behavior, commitment, and supply chain performance. Management Science 54(10), 1759-1773.

$\mathrm{Su}, \mathrm{X}$. and F. Zhang (2009). On the value of commitment and availability guarantees when selling to strategic consumers. Management Science 55(5), 713-726.

Swinney, R. (2011). Selling to strategic consumers when product value is uncertain: The value of matching supply and demand. Management Science 57(10), 1737-1751.

UPS (2014, June). Ups pulse of the online shopper.

Wall Street Journal (2012a, April 11). Can retailers halt 'showrooming'?

Wall Street Journal (2012b, Jan 23). Showdown over 'showrooming'.

Wall Street Journal (2013a, November). Fear of 'showrooming' fades.

Wall Street Journal (2013b, December). Rampant returns plague e-retailers. 
Wall Street Journal (2014, November). Warby Parker adds storefronts to its sales strategy.

Yin, R., Y. Aviv, A. Pazgal, and C. S. Tang (2009). Optimal markdown pricing: Implications of inventory display formats in the presence of strategic customers. Management Science 55(8), $1391-1408$.

Yu, M., L. Debo, and R. Kapuscinski (2015). Strategic waiting for consumer-generated quality information: Dynamic pricing of new experience goods. Management Science.

\section{Appendix A Detailed Analyses of Scenarios When Multiple Mech- anisms are Provided Simultaneously}

\section{A.1 Providing both Physical Showrooms and Availability Information}

With physical showrooms and availability information, consumer utilities are as follows

- utility from buying online directly: $u_{o}=\theta\left(v-p-h_{o}\right)-(1-\theta)\left(h_{o}+h_{r}\right)$

- utility from visiting store when store is in stock: $u_{s, i n}=-h_{s}+\theta(v-p)$

- utility from visiting store when store is out of stock: $u_{s, \text { out }}=-h_{s}+\theta\left(v-p-h_{o}\right)$

Then, if $u_{o}<u_{s, o u t}$, i.e.,

$$
h_{s}<(1-\theta)\left(h_{o}+h_{r}\right)
$$

consumers would always visit store, even if it is shown that store is out of stock. In this case, retailer profit $\pi=p E \min (\theta D, q)-c q+w E(\theta D-q)^{+}=(p-w) E \min (\theta D, q)-c q+w E \theta D$, and

thus the optimal store inventory level $q^{p a}=\theta \bar{F}^{-1}\left(\frac{c}{p-w}\right)$. Note condition 10 is equivalent to $\theta<\underline{\psi}^{p a}$ where $\underline{\psi}^{p a}=\min \left(\max \left(\frac{h_{o}+h_{r}-h_{s}}{h_{o}+h_{r}}, 0\right), 1\right)$, given $\theta \in(0,1)$.

If $u_{o} \in\left[u_{s, o u t}, u_{s, i n}\right)$, i.e.,

$$
h_{s} \in\left[(1-\theta)\left(h_{o}+h_{r}\right), h_{o}+(1-\theta) h_{r}\right)
$$

consumers would visit store if store is in stock but buy online directly if store is out of stock. In this case, retailer profit $\pi=p E \min (\theta D, q)-c q+w E(\theta D-q)^{+}-r E \frac{1-\theta}{\theta}(\theta D-q)^{+}=(p-$ 
$\left.w+r \frac{1-\theta}{\theta}\right) E \min (\theta D, q)-c q+(w \theta-r(1-\theta)) E D$, and thus the optimal store inventory level $q^{p a}=\theta \bar{F}^{-1}\left(\frac{c}{p-w+r \frac{1-\theta}{\theta}}\right)$. Note condition 11 is equivalent to $\theta \in\left[\underline{\psi}^{p a}, \tilde{\psi}^{p a}\right)$ where $\tilde{\psi}^{p a}=$ $\min \left(\max \left(\frac{h_{o}+h_{r}-h_{s}}{h_{r}}, 0\right), 1\right)$. Moreover, note if the critical fractile $\frac{c}{p-w+r \frac{1-\theta}{\theta}} \geq 1\left(\Leftrightarrow \theta \geq \frac{r}{(w+r-p+c)^{+}}\right.$, given $\theta \in(0,1))$, then $q^{p a}=0$, i.e., store is never in stock and thus consumers actually always buy online as a result.

If $u_{o} \geq u_{s, i n}$, i.e., $h_{s} \geq h_{o}+(1-\theta) h_{r}$ or $\theta \geq \tilde{\psi}^{p a}$, then consumers always buy online directly. In this case, retailer profit $\pi=w E \theta D-r E(1-\theta) D$. The optimal inventory level is just $q^{p a}=0$.

The following proposition summaries the discussion above, where $\bar{\psi}^{p a}=\min \left(\frac{r}{(w+r-p+c)^{+}}, \tilde{\psi}^{p a}\right)$ Proposition A.1.1. With physical showrooms and availability information, the market outcome is given as follows:

- If $\theta \leq \underline{\psi}^{p a}$, then consumers always visit store; $q^{p a}=\theta \bar{F}^{-1}\left(\frac{c}{p-w}\right)$;

- If $\theta \in\left[\underline{\psi}^{p a}, \bar{\psi}^{p a}\right)$, then consumers visit store if it is in stock but buy online directly if store is out of stock; $q^{p a}=\theta \bar{F}^{-1}\left(\frac{c}{p-w+r \frac{1-\theta}{\theta}}\right)$;

- If $\theta \geq \bar{\psi}^{p a}$, then consumers always buy online directly; $q^{p a}=0$.

\section{A.2 Providing both Physical Showrooms and Virtual Showrooms}

With virtual showrooms, there is a new customer pool. Then, having both physical showrooms and virtual showrooms is very similar to the case when there is only physical showrooms, simply replacing with a new set of parameters $\left(\theta^{\prime}\right.$ and $D^{\prime}$ (or $\left.F^{\prime}\right)$ ). Thus, similar to the proof of Proposition 2 . we can easily find the RE equilibrium (the proof of which is omitted):

Proposition A.2.1. With physical showrooms and virtual showrooms, there exists a threshold $\psi^{\text {pv }}$ such that

- if $\theta<\psi^{p v}$, then consumers visit store; $q^{p v}=\theta^{\prime} \bar{F}^{-1}\left(\frac{c}{p-w}\right)$

- if $\theta \geq \psi^{p v}$, then consumers buy online directly; $q^{p v}=0$. 


\section{A.3 Providing both Virtual Showrooms and Availability Information}

Again, note that with virtual showrooms, there is a new customer pool. Then, having both virtual showrooms and availability information is very similar to the case when there is only availability information, simply replacing with a new set of parameters $\left(\theta^{\prime}\right.$ and $D^{\prime}$ (or $\left.F^{\prime}\right)$ ). Thus, similar to the proof of Proposition 6, we can easily find the market outcome (the proof of which is omitted):

Proposition A.3.1. With virtual showrooms and availability information, there exists a threshold $\psi^{v a} \in\left[\psi^{v}, 1\right]$ such that the market outcome is given as follows:

- If $\theta<\psi^{v a}$, then consumers visit store if store is in stock, and buy online directly if store is out of stock; $q^{v a}=\theta^{\prime} \bar{F}^{\prime-1}\left(\frac{c}{p-w+r \frac{1-\theta^{\prime}}{\theta^{\prime}}}\right)$

- If $\theta \geq \psi^{v a}$, then consumers always buy online directly; $q^{v a}=0$.

\section{A.4 Providing All Three Mechanisms}

Similar to the previous two sections, we note that with virtual showrooms, there is a new customer pool. Then, having all three mechanisms is very similar to the case when there are both physical showrooms and availability information, simply replacing with a new set of parameters $\left(\theta^{\prime}\right.$ and $D^{\prime}$ $\left(\right.$ or $\left.F^{\prime}\right)$ ). Thus, similar to the discussion in Section A.1, we can easily find the market outcome (the proof of which is omitted):

Proposition A.4.1. With all three types of information, the market outcome is given as follows:

- If $\theta<\underline{\psi}^{p v a}$, then consumers always visit store; $q^{p v a}=\theta^{\prime} \bar{F}^{\prime-1}\left(\frac{c}{p-w}\right)$;

- If $\theta \in\left[\underline{\psi}^{p v a}, \bar{\psi}^{p v a}\right)$, then consumers visit store if it is in stock but buy online directly if store is out of stock; $q^{p v a}=\theta^{\prime} \bar{F}^{\prime-1}\left(\frac{c}{p-w+r \frac{1-\theta^{\prime}}{\theta^{\prime}}}\right)$;

- If $\theta \geq \bar{\psi}^{p v a}$, then consumers always buy online directly; $q^{p v a}=0$. 